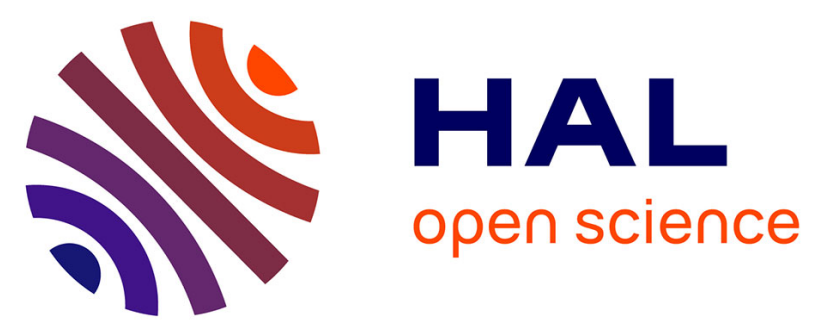

\title{
Improvement of electrochemical detection of transthyretin synthetic peptide and its amino acids on carbon electrodes: Glassy carbon versus amorphous carbon nitride a-CNx
}

Mathilde Faure, Florence Billon, I. Le Potier, A.-M Haghiri-Gosnet, Bernard Tribollet, Alain Pailleret, Claude Deslouis, Jean Gamby

\section{To cite this version:}

Mathilde Faure, Florence Billon, I. Le Potier, A.-M Haghiri-Gosnet, Bernard Tribollet, et al.. Improvement of electrochemical detection of transthyretin synthetic peptide and its amino acids on carbon electrodes: Glassy carbon versus amorphous carbon nitride a-CNx. Electrochimica Acta, 2019, 296, pp.251-258. 10.1016/j.electacta.2018.11.022 . hal-01929264

\section{HAL Id: hal-01929264 \\ https://hal.sorbonne-universite.fr/hal-01929264}

Submitted on 21 Nov 2018

HAL is a multi-disciplinary open access archive for the deposit and dissemination of scientific research documents, whether they are published or not. The documents may come from teaching and research institutions in France or abroad, or from public or private research centers.
L'archive ouverte pluridisciplinaire HAL, est destinée au dépôt et à la diffusion de documents scientifiques de niveau recherche, publiés ou non, émanant des établissements d'enseignement et de recherche français ou étrangers, des laboratoires publics ou privés. 


\section{Improvement of electrochemical detection of transthyretin synthetic peptide} and its amino acids on carbon electrodes: glassy carbon versus amorphous

\section{carbon nitride a-CNx}

\footnotetext{
M. Faure, ${ }^{a}$ F. Billon, ${ }^{a}$ I. Le Potier, ${ }^{b}$ A.-M. Haghiri-Gosnet, ${ }^{b}$ B. Tribollet, ${ }^{a}$ A. Pailleret, ${ }^{a}$ C. Deslouis, ${ }^{\mathrm{a}}$ and J. Gamby ${ }^{\mathrm{ab},}$

${ }^{a}$ Sorbonne Université, CNRS, Laboratoire Interfaces et Systèmes Electrochimiques (LISE, UMR 8235), 4 place Jussieu, F-75005, Paris, France.

${ }^{b}$ Centre de Nanosciences et de Nanotechnologies, CNRS, Univ. Paris-Sud, Université Paris-Saclay, C2N, Avenue de la Vauve, 91120, Palaiseau, France.
}

\footnotetext{
${ }^{1}$ ISE Member

* Corresponding author (Centre de Nanosciences et de Nanotechnologies, CNRS, Univ. Paris-Sud, Université Paris-Saclay): jean.gamby@c2n.upsaclay.fr Tel: +33170270670
} 


\begin{abstract}
Amorphous carbon nitride $a-\mathrm{CN}_{0.26}$ thin films were elaborated on transparent and conductive glass/indium-tin oxide (ITO) wafers to improve the electroanalytical detection of transthyretin peptide (PN) and specific amino acids (AA) from its sequence, which constitutes a great challenge for the diagnosis of transthyretin-related familial amyloïd polyneuropathy (ATTR). The naphthalene-2,3-dicarboxyaldehyde (NDA) label was used for the derivatization reaction of PN and AAs to form N-2-substituted-1-cyanobenz-[f]-isoindole derivatives (CBI) which are both fluorescent and electroactive. The results obtained on $a-\mathrm{CN}_{0.26}$ were compared with those observed on glassy carbon (GC) as a reference material. It was shown that a soft anodic pretreatment protocol on glass/ITO/a- $\mathrm{CN}_{0.26}$ electrode in a $\mathrm{KCl}$ aqueous solution drastically improved the performances of the CBI-PN and CBI-AA oxidation peak. The oxidation peak potential for all CBI derivatives varied in the same range than those measured on GC and pretreated glass/ITO/a-CN $\mathrm{CN}_{0.26}$, while no discrimination could be obtained on as-grown glass/ITO/a$\mathrm{CN}_{0.26}$ electrodes. For almost all the tested CBI derivatives, peak areas, full-widths at peak midheight, peak current density and their standard deviation (SD) values were improved on a pretreated $a-\mathrm{CN}_{0.26}$ electrode in comparison with GC.
\end{abstract}

Keywords: Transthyretin Peptide; Amorphous Carbon Nitride; Impedance Spectroscopy; Cyclic Voltammetry; Differential Pulse Voltammetry. 


\section{Introduction}

The detection and the quantification of small peptides such as transthyretin peptide (PN), a tryptic fragment of transthyretin (TTR), both constitute a great challenge for the diagnosis of transthyretin-related familial amyloïd polyneuropathy (ATTR) [1-6]. In order to enhance the detection sensitivity of this biomarker, likely to be useful for the detection of T49A ATTR mutation which is one of the most frequently reported ones in France [1,7] the common approach consists in the covalent derivatization of the amino acids (AA) residues of its sequence. For instance, one of the most fluorescent label widely used for this purpose is naphthalene-2,3dicarboxyaldehyde (NDA). Moreover, capillary electrophoresis (CE) coupled with optical detection such as laser induced fluorescence (CE-LIF) remains a powerful approach to analytically evaluate the derivatization reaction efficiency [8]. In brief, the derivatization reaction in presence of cyanide permits to form fluorescent N-2-substituted-1-cyanobenz-[f]-isoindole derivative (CBI) [9].

As CBI and NDA molecules are also electroactive, a property which was recently used to investigate the tagging efficiency of labelled CBI-PN and CBI-AA [5,6], a new challenge for the development of an innovative detection module in chip electrophoresis would be to link up in a single microchip the electrochemical and optical detections [10-13].

Several electrode materials can be used for the electrochemical detection and in particular the carbon based ones which appeared as promising sensors. Among them, carbon nitrides and their nanotubes (CNTs) have been developed as sensors for the detection of organic or biologic molecules (e.g. melamine [14], Chlorpyrifos [15], phenylethanolamine [16], ractopamine [17], and bilirubine [18]). In those examples, CNTs were associated with compounds such as graphene quantum dots or PolyOxoMetallates and they were inserted in thin films of molecular imprinted polymer. Specific cavities formed by the analytes to be detected (these latter were preliminary 
inserted and then removed before detection) allowed low detection limits in the picomolar range with an obvious selectivity. However, such films are generally deposited on Glassy Carbon (GC) electrodes, which prevents their use in the applications aimed in this work. In fact, the optical detection associated to the electrochemical one requires the mutual use of transparent wafer onto which a thin layer of a transparent and conductive material behaving as a polarizable electrode can be deposited. For this, the oxidation and/or reduction of the aqueous solvent should be minimized within a wide potential window and the electrode material has to present a fair electrochemical reactivity with respect to the targeted analytes to be detected. Therefore, transparent and conductive ITO-coated glass slides appeared to be the most appropriate for electrochemical measurements [19-26]. However, the width of the potential window is at most 2 V for ITO.

For the last decades, other carbon materials were purposely developed so as to widen the potential window in aqueous solvent $(\sim 3 \mathrm{~V})$, to improve the electrode reactivity and to lower the parasitic currents, and thus to become suitable for analytical applications [27-31]. In particular, diamond-like carbon (DLC), boron-doped diamond (BDD) or amorphous carbon nitride (a-CNx) materials, all elaborated as thin films, have shown excellent electroanalytical performances, e.g. stripping analysis for heavy metals detection [32-36], or organic analytes detection [37-39] below micromolar concentrations. However, these electrodes require electrochemical pre-treatments to improve their surface reactivity and to increase the width of the potential window. For instance, cathodic electrochemical pre-treatments carried out in an acidic medium, substantially improved the a-CNx reactivity as compared to as-grown samples or to anodically pre-treated ones [27-29]. In the case of organic analytes detection, it has been shown that an anodic pre-treatment in alkaline medium may afford better peaks separation as it worsens the reactivity towards one component of the mixture, e.g. of ascorbic acid and dopamine $[38,39]$ while a cathodic pre- 
treatment in a slightly acidic medium allows a fine detection of furosemide using the Square Wave Voltammetry (SWV) method [40].

Until now, most of the a-CNx layers were grown on doped silicon, [27,30-31,33-37,41-45] possibly as a consequence of their strong adhesion on this substrate that results probably from the formation of an intermediate layer of mixed composition [46]. Titanium was also shown to be a suitable substrate $[28,43,45]$, as well as stainless steel $[29,38-40]$, as both appear to be more appropriate for practical applications. For these three substrates, adhesion of a-CNx was strong enough even for low nitrogen content (x low) materials in which high internal mechanical stresses could have provoked delamination. Recently, ITO covered glass plates were also tested as substrates but the film properties were only investigated in air [46]. More recently, a further study of spectroscopic, microscopic and electrochemical characterization of several ITO/a-CNx electrodes was carried out both in air and in blocking electrode conditions, i.e. in the presence of the supporting electrolyte only [47].

In this applicative work, a- $\mathrm{CN}_{0.26}$ thin films were synthesized on ITO substrates for electrodes elaboration according to the protocol described in [47]. Then, a soft electrochemical pretreatment was developed to activate these electrodes instead of hard pre-treatment which could provoke delamination. Here "soft pre-treatment", as opposed to "hard pre-treatment", means that the potential excursion during the pre-treatment remains within the potential window in the former case, while it extends beyond it and is accompanied with gas evolution in the latter one. Finally, a derivatization reaction protocol leading to the formation of the electroactive CBI was used to compare the performances of the electroanalytical peak obtained during the detection of PN and of four specific amino acids of PN sequence on three different carbon electrode materials: as-grown $a$-CNx, pre-treated $a-\mathrm{CNx}$ and GC. 


\section{Experimental}

\subsection{Reagents and chemicals}

NDA, potassium cyanide, boric acid, lysine and serine were purchased from Sigma Aldrich (Saint-Quentin Fallavier, France). Methanol and sodium hydroxide were obtained from VWR (Fontenay-sous-Bois, France) and PN peptide (GPS1344), a synthetic peptide mimicking a 22AA tryptic fragment of interest for the diagnosis of T49A ATTR mutation, was purchased from Genepep (Prades le Lez, France). Histidine and threonine were obtained from Alfa Aesar (Karlsruhe, Germany).

The labelling step was performed in a $100 \mathrm{mM}$ borate buffer ( $\mathrm{pH} 9) / \mathrm{MeOH}(50 / 50 \mathrm{v} / \mathrm{v}$ ) solution. The molar ratio of NDA / CN was 1 and NDA / AA or NDA / PN was 100 (see scheme 1). The labelling protocol was previously optimized for an optimum buffer $\mathrm{pH}$ equal to the derivatized amino group $\mathrm{pKa}$ [6]. The final concentration of the CBI derivatives (amino acid or peptide) was $25 \mu \mathrm{M}$ (see scheme 2). The labelling time was about 15 minutes.

\subsection{Glass/ITO/ CNx electrode fabrication}

The glass slides $(7 \mathrm{~mm} \times 50 \mathrm{~mm} \times 1 \mathrm{~mm})$ provided by SOLEMS S.A. (Palaiseau, France) were coated with a conductive $100 \mathrm{~nm}$ thick ITO thin film initially deposited by using the PVD (Physical Vapor Deposition ) technique. Prior to $a$-CNx thin film deposition, glass/ITO wafers were first cleaned in ethanol, acetone, bi-distilled water and then underwent radio frequency ion etching (13.56 MHz). Thin $a$-CNx films were then deposited by using the DC magnetron sputtering technique from a graphite target in an argon and nitrogen based plasma. The reactor used was a 300S MP model from PLASSYS. The deposition phases were carried out with a power of $200 \mathrm{~W}$ for 20 minutes using a $0.4 \mathrm{~Pa}$ total pressure and a $15 \%$ partial pressure of nitrogen in the gas mixture. For delimiting the working electrode (WE) surface area, a $6 \mathrm{~mm}$ 
internal diameter Plexiglas tube was immobilised on the wafer. Thereafter, the glass/ ITO/ CNx wafer edges and the periphery of the $a$-CNx disk electrode that was situated outside the tube were isolated with epoxy resin. Due to this method, only a well-defined area $\left(0.282 \mathrm{~cm}^{2}\right)$ of the WE electrode was in contact with the electrolyte. The $a$-CNx thin film stoichiometry and thickness were determined with the help of XPS and SEM-FEG techniques respectively and led to $a$ - $\mathrm{CN}_{0.26}$ as formula and a $320 \mathrm{~nm}$ thickness, respectively [47].

\subsection{Apparatus}

All the electrochemical measurements, i.e. cyclic voltammetry $(\mathrm{CV})$, electrochemical impedance spectroscopy (EIS) and differential pulse voltammetry (DPV) were performed by using a Biologic SP-300 electrochemical analysis system and its EC-lab software. Experiments were performed in a three-electrode cell. The reference and the counter electrodes were a saturated calomel electrode (SCE) and a platinum grid (Pt), respectively. The CV experiments were carried out at a $50 \mathrm{mV} \mathrm{s}^{-1}$ scan rate. The selected DPV parameters such as modulation time (100 ms), modulation amplitude $(7.5 \mathrm{mV})$, pulse period $(200 \mathrm{~ms})$ and scan rate $\left(25 \mathrm{mV} \mathrm{s}^{-1}\right)$ have been optimized to obtain well-defined analytical curves. These latter were all corrected by eliminating the DPV background response that was recorded in a control experiment. For the EIS measurements, the experimental curves were recorded with a $10 \mathrm{mV} \mathrm{AC}$ signal amplitude in a frequency range situated between $100 \mathrm{kHz}$ and $50 \mathrm{mHz}$ (5 points per decade). The experimental curves were simulated using a homemade software (SIMAD) designed at LISE Laboratory. 


\section{Results and discussion}

\subsection{Anodic electrochemical pre-treatment of $a-\mathrm{CN}_{0.26}$ electrodes}

As mentioned in the introduction, $a-\mathrm{CN}_{\mathrm{x}}$ electrodes were generally electrochemically pre-treated in a $0.5 \mathrm{M} \mathrm{H}_{2} \mathrm{SO}_{4}$ acidic aqueous medium or with $0.1 \mathrm{M} \mathrm{KOH}$ alkaline aqueous medium [38]. These protocols have been tested but they were shown to be detrimental in our case as they often created some holes in the $a-\mathrm{CN}_{0.26}$ layer and sometimes its delamination from the glass/ITO wafer (see Figure S1 in the supplementary information file). As a consequence, a soft anodic electrochemical pre-treatment was preferred. It consisted in cycling the potential at $50 \mathrm{mV} \mathrm{s}^{-1}$ between -1 and $+1.4 \mathrm{~V} / \mathrm{SCE}$ for $5 \mathrm{~min}$ in $0.5 \mathrm{M} \mathrm{KCl}$ aqueous solution. In these conditions, two reactions occurred at the $a$ - $\mathrm{CN}_{0.26}$ electrode, the water and/or chloride oxidation reactions leading ultimately to $\mathrm{O}_{2}$ and/or $\mathrm{Cl}_{2}$ gas evolutions when the applied potential was positive, and hydrogen evolution resulting from water reduction for negative values of the applied potential. The electrochemical reactivity was checked before and after the pre-treatment protocol by performing $\mathrm{CV}$ and EIS measurements in $0.5 \mathrm{M} \mathrm{KCl}$ aqueous solutions containing equimolar concentrations $(10 \mathrm{mM})$ of $\left[\mathrm{Fe}(\mathrm{III})(\mathrm{CN})_{6}\right]^{3-}$ and $\left[\mathrm{Fe}(\mathrm{II})(\mathrm{CN})_{6}\right]^{4-}$ well known to form together a reversible redox couple. The EIS spectra were recorded at $0.21 \mathrm{~V} / \mathrm{SCE}$, that corresponds to the equilibrium potential of the $\left[\mathrm{Fe}(\mathrm{III})(\mathrm{CN})_{6}\right]^{3-} /\left[\mathrm{Fe}(\mathrm{II})(\mathrm{CN})_{6}\right]^{4-}$ redox couple in our experimental conditions.

The experiments were repeated for three $a-\mathrm{CN}_{0.26}$ electrode samples in order to check the data reproducibility. The comparison of the voltammograms obtained before and after pre-treatment shows an increase of the peak current density, $J_{\mathrm{p}}$, and a decrease of the peak potential difference, $\Delta E_{\mathrm{p}}$, calculated from the difference between the reduction and oxidation peak potentials (Figure 1). As listed in Table 1, the $\Delta E_{\mathrm{p}}$ values determined before and after pre-treatment were about 720 $\pm 60 \mathrm{mV}$ and $336 \pm 45 \mathrm{mV}$, respectively. Although the $\Delta E_{\mathrm{p}}$ value has been divided by two after the activation step, it is still far from the $59 \mathrm{mV}$ value expected at $298.16 \mathrm{~K}$ in the case of a 
monoelectronic and reversible electron transfer reaction. It suggests that, even though the electrochemical pre-treatment was found to be highly beneficial, the kinetics of the charge transfer at the $a-\mathrm{CN}_{0.26}$ electrode/solution interface remained slow.

Regarding the EIS spectra shown in Figure 2, they are divided into two parts, a capacitive loop at high frequencies $(10 \mathrm{kHz}-1 \mathrm{~Hz})$ and a Warburg diffusion impedance, $W$, which is marked by the beginning of a straight line at low frequencies $(1 \mathrm{~Hz}-50 \mathrm{mHz})$. The high-frequency limit of the diagram and the diameter of the loop correspond to the value of the electrolyte resistance, $R_{\mathrm{e}}$, and to the charge transfer resistance $R_{\mathrm{t}}$, respectively. In order to evaluate the ideality of the capacitive behaviour, we plotted $\log (-\operatorname{Im}(\mathrm{Z}))$ as a function of $\log ($ frequency $(\mathrm{Hz}))$. These log-log plots led to $\alpha$-slope values comprised between 0.8 and 0.9 . These values underline a non-ideal behavior of the capacitance and justify the use of a constant phase element, CPE, in the electric equivalent circuit presented in scheme 3.

The simulation procedure of the EIS data analysis was performed using the analytical expression that corresponds to the electrical equivalent circuit on scheme 3 taking into account, as previously highlighted, a CPE $(Q)$ instead of an ideal capacitor $C$, as follows,

$Z_{g}=R_{e}+\frac{R_{t}+W}{1+Q\left(R_{t}+W\right)(j \omega)^{\alpha}}$

where $\omega$ is the angular frequency $\left(\mathrm{rad} \mathrm{s}^{-1}\right)$, defined by $\omega=2 \pi f$, and $f$ is the frequency $(\mathrm{Hz})$.

As summarized in Table 2, the values obtained after regression show low $\chi^{2}$ values and highlight the fact that the electrochemical properties of as-grown $a-\mathrm{CN}_{0.26}$ thin films deposited on ITO are reproducible.

In the case of a distribution of time constants along the surface, the use of Brug formula [48] permits an estimation of the equivalent double layer capacitance, $C_{\mathrm{d}}$, which is expressed as a function of $Q, \alpha, R_{\mathrm{e}}$, and $R_{\mathrm{t}}$, as follows, 
$C_{d}=Q^{\frac{1}{\alpha}} R_{\Omega}^{\frac{1-\alpha}{\alpha}}$

where, $R_{\Omega}$, the combination of the electrolyte resistance and the charge transfer resistance, is defined as follows,

$\frac{1}{R_{\Omega}}=\frac{1}{R_{e}}+\frac{1}{R_{t}}$

The double layer capacitance estimated from the Brug formula (Equations 2 and 3) is equal to 7.9 $\mu \mathrm{F} \mathrm{cm}{ }^{-2}$ and $7.6 \mu \mathrm{F} \mathrm{cm}^{-2}$, for as-grown and pre-treated $a-\mathrm{CN}_{0.26}$, respectively. These capacitance values are close enough to the value of $8 \mu \mathrm{F} \mathrm{cm}^{-2}$ determined in a $0.5 \mathrm{M} \mathrm{KCl}$ supporting aqueous electrolyte alone.

In addition, from the $R_{\mathrm{t}}$ values, we can also determine the heterogeneous charge transfer rate constant $k_{0}$, which is inversely proportional to the charge transfer resistance, $R_{\mathrm{t}, \eta \rightarrow 0}$ (i.e. at the zero overpotential $(\eta \rightarrow 0))$, as follows

$k_{0}=\frac{R T}{F^{2} S R_{t, \eta \rightarrow 0}[C]}$

with, $T$, the temperature, $R$, the molar gas constant, $F$, the Faraday constant, [C] the molar concentration of the electroactive species and $S$, the surface area of the working electrode.

While in both cases, $C_{\mathrm{d}}$ values remained in the same order of magnitude, the values of $k_{0}$ have been improved by 3 -fold thanks to the activation protocol. Indeed, $k_{0}$ has been found to be equal to $6.25 \times 10^{-5} \mathrm{~cm} \mathrm{~s}^{-1}$ and $1.7 \times 10^{-4} \mathrm{~cm} \mathrm{~s}^{-1}$, for as-grown and pre-treated $a-\mathrm{CN}_{0.26}$, respectively. The activation protocol plays an important role on the improvement of the charge transfer resistance but none on the double layer capacitance. One can note that this $\mathrm{k}_{0}$ value for the pre-treated 
sample is much lower by about two orders of magnitude [29] than the one obtained on a stainless steel substrate after a severe cathodic pre-treatment.

\subsection{Detection and characterization of labelled biomolecules}

\subsubsection{Differential Pulse Voltammetry}

Figure 3 shows DP Voltammograms for 4 CBI-AA and CBI-PN performed on as-grown $a$ $\mathrm{CN}_{0.26}$

Table 3 shows the values of peak potential, $E_{\mathrm{p}}$, peak area, $A$, peak current densities, $J_{\mathrm{p}}$, and fullwidth at peak mid-height, $L_{1 / 2}$, for the 4 CBI-AA and CBI-PN. The DP Voltammograms obtained on as-grown $a$ - $\mathrm{CN}_{0.26}$ electrodes show broad peaks and low peak current densities. In addition, except for CBI-lysine, the peak potential values are close enough and their standard deviations (SD) do not permit to clearly identify the labelled AA. The flattened peak with large $L_{1 / 2}$ values also indicates a loss of reversibility for the charge transfer on as-grown $a-\mathrm{CN}_{0.26}$. As a consequence, the anodic pre-treatment protocol step previously described has been exploited in order to gain electrochemical reactivity and to improve the performances of the anodic detection of labelled species, thanks to a better peak separation.

Figure 4 shows the obtained results for 4 CBI-AA and CBI-PN detected on the pre-treated $a$ $\mathrm{CN}_{0.26}$. Table 4 summarizes the peak characteristics from data displayed on Figure 4. As expected, the pre-treatment protocol permits an improvement of the peak resolution observed on on $a-\mathrm{CN}_{0.26}$ for each labelled biomolecule.

The first advantage is that the peak potential of CBI-R decreased in average from 640 to $560 \mathrm{mV}$ with a SD decreasing also in average from 38 to $3.8 \mathrm{mV}$. Secondly, the peak areas were multiplied by 2 or 4 and the peak current densities by 3 to 9 in the case the CBI-R. The expansion factors of peak area and current density that result from this electrochemical activation process 
are provided in Table 5. Thirdly, the full-width at peak mid-height decreased in average from 234 to $148 \mathrm{mV}$. In other words, the full-widths at mid-height have lost in average $60 \%$ of their value after pre-treatment.

It appears therefore that the electrochemical pre-treatment of $a-\mathrm{CN}_{0.26}$ improved the peaks resolution and produced simultaneously an increase of the peak area and the current density for the targeted analytes. As a consequence, it also permitted to better discriminate the CBI-AA and CBI-PN. In addition, the CBI species are well-defined by their full-width at mid-height, $L_{1 / 2}$.

\subsubsection{Comparison between $a-\mathrm{CNx}$ and glassy carbon electrode}

As displayed in Figure 5, the data obtained on GC in a previous work [5] were compared with those obtained on pre-treated $a-\mathrm{CN}_{0.26}$. As listed in tables 3 and 4 , the peaks are better defined on pre-treated $a-\mathrm{CN}_{0.26}$ according to their $J_{\mathrm{p}}$ and $L_{1 / 2}$ values, while $E_{\mathrm{p}}$ still varies in the same order. Indeed, the oxidation peak potential ranking on both carbon electrodes (GC and pre-treated $a$ $\left.\mathrm{CN}_{0.26}\right)$ is $E_{\mathrm{p}(\mathrm{CBI}-\text { lysine })}<E_{\mathrm{p}(\mathrm{CBI}-\mathrm{PN})}<E_{\mathrm{p}(\mathrm{CBI}-\text {-histidine })}<E_{\mathrm{p}(\mathrm{CBI} I \text {-threonine })}<\mathrm{E}_{\mathrm{p}(\mathrm{CBI}-\text {-serine })}$. It appears that the CBI-AA with their electrically charged AA side moieties (lysine and histidine) are more easily oxidized than AA with its polar uncharged side chains (serine and threonine). Concerning the labelled peptide PN, CBI-PN, lysine and threonine are located in C-terminal and N-terminal peptidic chain position, respectively. This explains why the CBI-PN oxidation peak potential was found at an intermediate value (552 mV/SCE) between those of CBI-lysine (537 mV/SCE) and CBI-threonine $(580 \mathrm{mV} / \mathrm{SCE})$.

In order to compare the obtained parameters such as $L_{1 / 2}, J_{\mathrm{p}}$, and the peak area, histograms were plotted with the AA (see Figures 6A-C) according to the experimental data collected with different electrodes, i.e. glassy carbon, as-grown $a-\mathrm{CN}_{0.26}$ and pre-treated $a$ - $\mathrm{CN}_{0.26}$. We note that 
the peaks are thinner and show better resolution on pre-treated $a-\mathrm{CN}_{0.26}$ electrode in comparison with as-grown $a-\mathrm{CN}_{0.26}$ and $\mathrm{GC}$ electrodes.

For instance, as shown in Figure 6A, the values of $L_{1 / 2}$ were found to be much larger on as-grown $a$ - $\mathrm{CN}_{0.26}$ compared with both other electrodes. The pre-treated $a-\mathrm{CN}_{0.26}$ electrode provides thinner peaks for CBI-lysine, CBI-histidine and CBI-threonine, as well as a full-width at midheight that is 30 or $40 \mathrm{mV}$ lower, while for CBI-serine, $L_{1 / 2}$ was $40 \mathrm{mV}$ lower on GC than on pretreated $a-\mathrm{CN}_{0.26}$. Concerning the peak current density plotted in Figure $6 \mathrm{~B}$, we observed that $J_{\text {pre- }}$

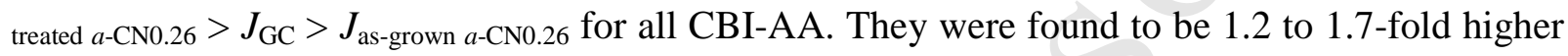
on pre-treated $a-\mathrm{CN}_{0.26}$ compared with GC, while they remain 3 to 9-fold lower on as-grown $a$ $\mathrm{CN}_{0.26}$.

In Figure 6C, the comparison of peak areas for the three electrodes shows that $A_{\text {pre-treated } a \text {-CN0.26 }}>$ $A_{\mathrm{GC}}>A_{\text {as-grown } a \text {-CN0.26 }}$ for CBI-histidine, CBI-threonine and CBI-lysine, while for CBI-serine, $A_{\mathrm{GC}}$ $\geq A_{\text {pre-treated } a \text {-CN0.26 }}>A_{\text {as-grown } a \text {-CN0.26. }}$

In summary, the detection on glassy carbon was found to be more efficient than on as-grown $a$ $\mathrm{CN}_{0.26}$ but much less efficient than on pre-treated $a-\mathrm{CN}_{0.26}$, a lower efficiency being systematically associated with lower peak areas and current densities and very large full-widths at peak mid-height. In addition, although the peak characteristics were found better for CBI-lysine, CBI-histidine and CBI-threonine on pre-treated $a-\mathrm{CN}_{0.26}$ in comparison with $\mathrm{GC}$, the characteristics of CBI-serine were closely similar on pre-treated $a-\mathrm{CN}_{0.26}$ and GC. Regarding the plotted histograms, we can assume that when the working electrode materials possess a sufficient reactivity, peak area depends mainly on the amino acids labelling and less on the electrode material, while the full-width at mid-height, $L_{1 / 2}$, and $J$ values depend more on the characteristics of the electrode material. 


\section{Conclusion}

Amorphous carbon nitride $\left(a-\mathrm{CN}_{0.26}\right)$ thin films were deposited on conductive glass/ITO slides by using the DC magnetron sputtering technique, a graphite target and a plasma containing a $15 \%$ $\mathrm{N}_{2}$ partial pressure. The stoichiometry of the $a-\mathrm{CN}_{0.26}$ thin film was determined with the help of XPS measurements. It was demonstrated that a soft anodic electrochemical pre-treatment on glass/ITO/a- $\mathrm{CN}_{0.26}$ electrode performed in a $\mathrm{KCl}$ aqueous solution can drastically improve characteristics of the oxidation peak of amino acids or peptide labelled with an electroactive label. Indeed, the DPV peaks obtained on glass/ITO/ as-grown $a-\mathrm{CN}_{0.26}$ possess a very important full-width at peak mid-height and a low peak current density for all detected biomolecules whereas full-widths at mid-height are smaller, peak current density increases and peak areas enlarge on glass/ITO/ pre-treated $a-\mathrm{CN}_{0.26}$. Data obtained with pre-treated $a$ - $\mathrm{CN}_{0.26}$ were also compared with those obtained on glassy carbon used as a reference material. Although the oxidation peak potential varies in the same range than those measured on glassy carbon and glass/ITO/as grown $a-\mathrm{CN}_{0.26}$ for all the CBI derivatives, the peak characteristics, i.e. the fullwidths at peak mid-height, the peak areas and the peak current density, as well as their SD values all appeared to be substantially improved on pre-treated $a-\mathrm{CN}_{0.26}$ after comparison with those obtained on glassy carbon, for almost all tested biomolecules.

\section{Acknowledgements}

This research was supported by the French ANR (Agence Nationale de la Recherche) in the context of the P2N "DIMIPOLE" project. The authors are also grateful to A. Pallandre for fruitful discussions. 


\section{References}

[1] L.H. Connors, A. Lim, T. Prokaeva, V.A. Roskens, C.E. Costello, Tabulation of human transthyretin (TTR) variants, 2003, Amyloid, 10 (2003) 160-184.

[2] Y. Ando, New therapeutic approaches for familial amyloidotic polyneuropathy (FAP), Amyloid, 10 Suppl 1 (2003) 55-66.

[3] Y. Ando, M. Nakamura, S. Araki, Transthyretin-related familial amyloidotic polyneuropathy, Arch. Neurol., 62 (2005) 1057-1062.

[4] S.M. Johnson, S. Connelly, C. Fearns, E.T. Powers, J.W. Kelly, The Transthyretin Amyloidoses: From Delineating the Molecular Mechanism of Aggregation Linked to Pathology to a Regulatory-Agency-Approved Drug, J. Mol. Biol., 421 (2012) 185-203.

[5] M. Faure, S. Korchane, P.I. Le, A. Pallandre, C. Deslouis, A.-M. Haghiri-Gosnet, J. Gamby, Investigating of labelling and detection of transthyretin synthetic peptide derivatized with naphthalene-2,3-dicarboxaldehyde, Talanta, 116 (2013) 8-13.

[6] M. Faure, I. Le Potier, A. Pallandre, S. Chebil, A.-M. Haghiri-Gosnet, C. Deslouis, E. Maisonhaute, J. Gamby, Determination of the isomeric forms proportion of fluorogenic naphthalene-2,3-dicarboxaldehyde in a binary mixture of water:methanol using electrochemical methods, Talanta, 148 (2016) 494-501.

[7] V. Planté-Bordeneuve, J. Carayol, A. Ferreira, D. Adams, F. Clerget-Darpoux, M. Misrahi, G. Said, C. Bonaïti-Pellié, Genetic study of transthyretin amyloid neuropathies: carrier risks among French and Portuguese families, J. Med. Genet., 40 (2003) e120-e120.

[8] S. Korchane, A. Pallandre, C. Przybylski, C. Poas, F. Gonnet, M. Taverna, R. Daniel, I. Le Potier, Derivatization strategies for CE-LIF analysis of biomarkers: Toward a clinical diagnostic of familial transthyretin amyloidosis, Electrophoresis, 35 (2014) 1050-1059.

[9] R.G. Carlson, K. Srinivasachar, R.S. Givens, B.K. Matuszewski, New derivatizing agents for amino acids and peptides. 1. Facile synthesis of $\mathrm{N}$-substituted 1-cyanobenz[f]isoindoles and their spectroscopic properties, J. Org. Chem., 51 (1986) 3978-3983.

[10] C. Yi, Q. Zhang, C.-W. Li, J. Yang, J. Zhao, M. Yang, Optical and electrochemical detection techniques for cell-based microfluidic systems, Anal. Bioanal. Chem., 384 (2006) 1259-1268.

[11] O. Yassine, P. Morin, O. Dispagne, L. Renaud, L. Denoroy, P. Kleimann, K. Faure, J.L. Rocca, N. Ouaini, R. Ferrigno, Electrophoresis PDMS/glass chips with continuous on-chip derivatization and analysis of amino acids using naphthalene-2,3-dicarboxaldehyde as fluorogenic agent, Anal. Chim. Acta, 609 (2008) 215-222.

[12] M. Faure, A. Pallandre, S. Chebil, I. Le Potier, M. Taverna, B. Tribollet, C. Deslouis, A.-M. Haghiri-Gosnet, J. Gamby, Improved electrochemical detection of a transthyretin synthetic peptide in the nanomolar range with a two-electrode system integrated in a glass/PDMS microchip, Lab Chip, 14 (2014) 2800-2805.

[13] J.V. Pagaduan, V. Sahore, A.T. Woolley, Applications of microfluidics and microchip electrophoresis for potential clinical biomarker analysis, Anal. Bioanal. Chem., 407 (2015) 69116922.

[14] M.L. Yola, T. Eren, N. Atar, A Molecular Imprinted Voltammetric Sensor Based on Carbon Nitride Nanotubes: Application to Determination of Melamine, J. Electrochem. Soc., 163 (2016) B588-B593.

[15] M.L. Yola, N. Atar, A Highly Efficient Nanomaterial with Molecular Imprinting Polymer: Carbon Nitride Nanotubes Decorated with Graphene Quantum Dots for Sensitive Electrochemical Determination of Chlorpyrifos, J. Electrochem. Soc., 164 (2017) B223-B229. 
[16] M.L. Yola, N. Atar, Phenylethanolamine A (PEA) Imprinted Polymer on Carbon Nitride Nanotubes/Graphene Quantum Dots/Core-Shell Nanoparticle Composite for Electrochemical PEA Detection in Urine Sample, J. Electrochem. Soc., 165 (2018) H1-H9.

[17] S. Mert, B. Bankoğlu, A. Özkan, N. Atar, M.L. Yola, Electrochemical sensing of ractopamine by carbon nitride nanotubes/ionic liquid nanohybrid in presence of other $\beta$-agonists, J. Mol. Liq., 254 (2018) 8-11.

[18] M.L. Yola, C. Göde, N. Atar, Molecular imprinting polymer with polyoxometalate/carbon nitride nanotubes for electrochemical recognition of bilirubin, Electrochim. Acta., 246 (2017) 135-140.

[19] X. Sun, K.D. Gillis, On-Chip Amperometric Measurement of Quantal Catecholamine Release Using Transparent Indium Tin Oxide Electrodes, Anal. Chem., 78 (2006) 2521-2525.

[20] T.L. Edwards, J.C. Harper, R. Polsky, D.M. Lopez, D.R. Wheeler, A.C. Allen, S.M. Brozik, A parallel microfluidic channel fixture fabricated using laser ablated plastic laminates for electrochemical and chemiluminescent biodetection of DNA, Biomicrofluidics, 5 (2011) 044115.

[21] M.A. Hasnat, A.J. Gross, S.E.C. Dale, E.O. Barnes, R.G. Compton, F. Marken, A dual-plate ITO-ITO generator-collector microtrench sensor: surface activation, spatial separation and suppression of irreversible oxygen and ascorbate interference, Analyst, 139 (2014) 569-575.

[22] C. Li, H. Jiang, Fabrication and Characterization of Flexible Electrowetting on Dielectrics (EWOD) Microlens, Micromachines, 5 (2014) 432-441.

[23] M.T. Dang, J. Lefebvre, J.D. Wuest, Recycling Indium Tin Oxide (ITO) Electrodes Used in Thin-Film Devices with Adjacent Hole-Transport Layers of Metal Oxides, ACS Sustain. Chem. Eng., 3 (2015) 3373-3381.

[24] W. Hilber, Stimulus-active polymer actuators for next-generation microfluidic devices, Appl. Phys. A: Mater. Sci. Process, 122 (2016) 751.

[25] S. Bouden, A. Dahi, F. Hauquier, H. Randriamahazaka, J. Ghilane, Multifunctional Indium Tin Oxide Electrode Generated by Unusual Surface Modification, Sci. Rep., 6 (2016) 36708.

[26] E.H. Kim, S.H. Cho, J.H. Lee, B. Jeong, R.H. Kim, S. Yu, T.-W. Lee, W. Shim, C. Park, Organic light emitting board for dynamic interactive display, Nat. Commun., 8 (2017) 14964.

[27] M. Benlahsen, H. Cachet, S. Charvet, C. Debiemme-Chouvy, C. Deslouis, A. Lagrini, V. Vivier, Improvement and characterization of the electrochemical reactivity of amorphous carbon nitride electrodes, Electrochem. Commun., 7 (2005) 496-499.

[28] P. Tamiasso-Martinhon, H. Cachet, C. Debiemme-Chouvy, C. Deslouis, Thin films of amorphous nitrogenated carbon a-CNx: Electron transfer and surface reactivity, Electrochim. Acta., 53 (2008) 5752-5759.

[29] A. Benchikh, C. Debiemme-Chouvy, H. Cachet, A. Pailleret, B. Saidani, L. Beaunier, M.H. Berger, C. Deslouis, Influence of electrochemical pre-treatment on highly reactive carbon nitride thin films deposited on stainless steel for electrochemical applications, Electrochim. Acta., 75 (2012) 131-138.

[30] H. Cachet, C. Debiemme-Chouvy, C. Deslouis, A. Lagrini, V. Vivier, Correlation between electrochemical reactivity and surface chemistry of amorphous carbon nitride films, Surf. Interface Anal., 38 (2006) 719-722.

[31] Y.V. Pleskov, M.D. Krotova, V.I. Polyakov, A.V. Khomich, A.I. Rukovishnikov, B.L. Druz, I. Zaritskiy, Electrochemical behaviour of a-C:N:H films, J. Electroanal. Chem., 519 (2002) 6064.

[32] A. Zeng, E. Liu, S.N. Tan, S. Zhang, J. Gao, Cyclic Voltammetry Studies of Sputtered Nitrogen Doped Diamond-Like Carbon Film Electrodes, Electroanalysis, 14 (2002) 1110-1115. 
[33] N.W. Khun, E. Liu, H.W. Guo, Cyclic Voltammetric Behavior of Nitrogen-Doped Tetrahedral Amorphous Carbon Films Deposited by Filtered Cathodic Vacuum Arc, Electroanalysis, 20 (2008) 1851-1856.

[34] K. Yoo, B. Miller, X. Shi, R. Kalish, Copper Electrodeposition and Dissolution on Tetrahedral Amorphous Carbon Incorporating Nitrogen, J. Electrochem. Soc., 148 (2001) C95C101.

[35] N.W. Khun, E. Liu, Linear sweep anodic stripping voltammetry of heavy metals from nitrogen doped tetrahedral amorphous carbon thin films, Electrochim. Acta., 54 (2009) 28902898.

[36] A. Zeng, E. Liu, S.N. Tan, S. Zhang, J. Gao, Stripping Voltammetric Analysis of Heavy Metals at Nitrogen Doped Diamond-Like Carbon Film Electrodes, Electroanalysis, 14 (2002) 1294-1298.

[37] R.A. Medeiros, R. Matos, A. Benchikh, B. Saidani, C. Debiemme-Chouvy, C. Deslouis, R.C. Rocha-Filho, O. Fatibello-Filho, Amorphous carbon nitride as an alternative electrode material in electroanalysis: Simultaneous determination of dopamine and ascorbic acid, Anal. Chim. Acta,, 797 (2013) 30-39.

[38] R.A. Medeiros, A. Benchick, R.C. Rocha-Filho, O. Fatibello-Filho, B. Saidani, C. Debiemme-Chouvy, C. Deslouis, Simultaneous detection of ascorbic acid and dopamine with electrochemically pre-treated carbon nitride electrodes: Comparison with boron-doped diamond electrodes, Electrochem. Commun., 24 (2012) 61-64.

[39] R.A. Medeiros, M. Baccarin, O. Fatibello-Filho, R.C. Rocha-Filho, C. Deslouis, C. Debiemme-Chouvy, Comparative Study of Basal-Plane Pyrolytic Graphite, Boron-Doped Diamond, and Amorphous Carbon Nitride Electrodes for the Voltammetric Determination of Furosemide in Pharmaceutical and Urine Samples, Electrochim. Acta., 197 (2016) 179-185.

[40] G.M. Swain, R. Ramesham, The electrochemical activity of boron-doped polycrystalline diamond thin film electrodes, Anal. Chem., 65 (1993) 345-351.

[41] K. Yoo, B. Miller, R. Kalish, X. Shi, Electrodes of Nitrogen Incorporated Tetrahedral Amorphous Carbon A Novel Thin Film Electrocatalytic Material with Diamond like Stability, Electrochem. Solid-State Lett., 2 (1999) 233-235.

[42] A. Lagrini, C. Deslouis, H. Cachet, M. Benlahsen, S. Charvet, Elaboration and electrochemical characterization of nitrogenated amorphous carbon films, Electrochem. Commun., 6 (2004) 245-248.

[43] A. Lagrini, S. Charvet, M. Benlahsen, H. Cachet, C. Deslouis, On the relation between microstructure and electrochemical reactivity of sputtered amorphous carbon nitride electrodes, Diamond Relat. Mater., 16 (2007) 1378-1382.

[44] A. Zeng, M.M.M. Bilek, D.R. McKenzie, P.A. Lay, A. La Fontaine, V.J. Keast, Correlation between film structures and potential limits for hydrogen and oxygen evolutions at a-C:N film electrochemical electrodes, Carbon, 46 (2008) 663-670.

[45] T. Fu, Y. Zheng, Y.G. Shen, Interface structure of sputter deposited CNx film on silicon substrate, Mater. Lett., 62 (2008) 2685-2687.

[46] J.C. Byers, P. Tamiasso-Martinhon, C. Deslouis, A. Pailleret, O.A. Semenikhin, Atomic Force Microscopy Studies of Carbon Nitride (CNx) Films Deposited on a Conducting Polymer Substrate, J. Phys. Chem. C, 114 (2010) 18474-18480.

[47] M. Faure, F. Billon, A.M. Haghiri-Gosnet, B. Tribollet, C. Deslouis, A. Pailleret, J. Gamby, Influence of the atomic nitrogen content in amorphous carbon nitride thin films on the modulation of their polarizable interfaces properties, Electrochim. Acta., 280 (2018) 238-247. 
[48] G.J. Brug, A.L.G. van den Eeden, M. Sluyters-Rehbach, J.H. Sluyters, The analysis of electrode impedances complicated by the presence of a constant phase element, J. electroanal. chem. interfacial electrochem., 176 (1984) 275-295. 


\section{Tables}

\section{Table1}

\begin{tabular}{llll}
\hline$a-\mathrm{CN}_{0.26}$ & $J_{\text {red }}\left(\mathrm{A} \mathrm{cm}^{2}\right)$ & $J_{\mathrm{ox}}\left(\mathrm{A} \mathrm{cm}^{2}\right)$ & $\Delta E_{\mathrm{p}}(\mathrm{mV})$ \\
\hline as-grown & $1.0 \times 10^{-3}$ & $1.1 \times 10^{-3}$ & $720 \pm 60$ \\
& & & \\
\hline Pre-treated & $1.9 \times 10^{-3}$ & $1.8 \times 10^{-3}$ & $336 \pm 45$ \\
& & & \\
\hline
\end{tabular}

Table 1: Values of the peak current densities, $J_{\mathrm{ox}}, J_{\text {red }}$ and the peak potential difference, $\Delta E_{\mathrm{p}}$ before and after the pre-treatment protocol. 
Table 2

as-grown $a-\mathrm{CN}_{0.26}$

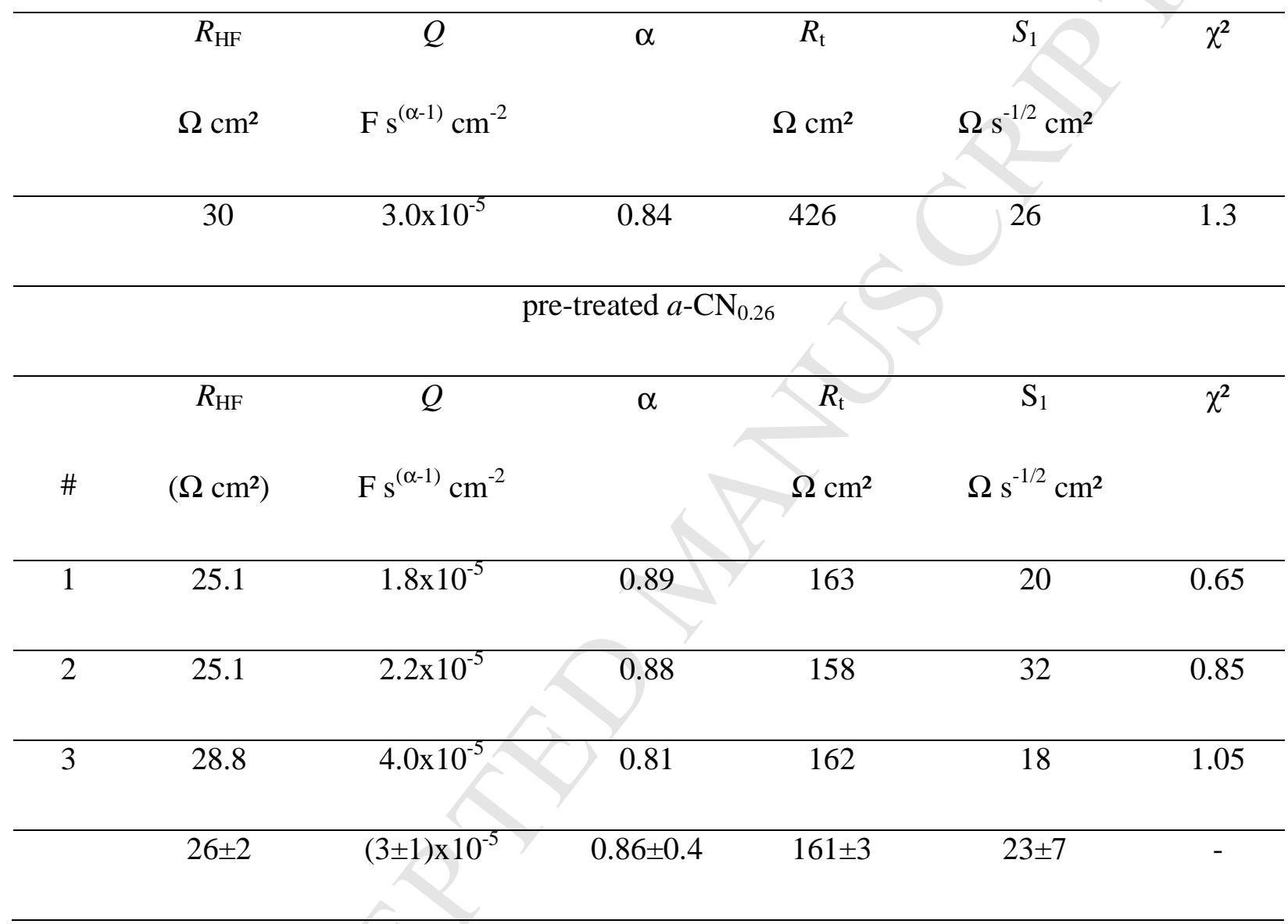

Table 2. Fitting parameters of impedance $\mathrm{Z}_{\mathrm{g}}(\omega)$ (see also equation 1) before and after $a-\mathrm{CN}_{0.26}$ pre-treatment in Figure 2. $S_{1}$ is the Warburg coefficient, and the values of the resulting $\chi^{2}$ statistic were obtained with errors of fitted values, $\sigma=0.01$, for frequency ranging from $100 \mathrm{kHz}$ to 50 $\mathrm{mHz}$ 
Table 3

\begin{tabular}{ccccc}
\hline CBI-R & $E_{\mathrm{p}}(\mathrm{mV} / \mathrm{SCE})$ & Area $\left(10^{-5}\right)$ & $L_{1 / 2}(\mathrm{mV})$ & $J_{\mathrm{p}}\left(10^{-5} \mathrm{~mA} \mathrm{~cm}^{-2}\right)$ \\
\hline Serine & $650 \pm 50$ & $0.9 \pm 0.1$ & 280 & $3.1 \pm 0.7$ \\
\hline Threonine & $650 \pm 60$ & $1.3 \pm 0.7$ & 250 & $4.1 \pm 0.9$ \\
\hline Histidine & $640 \pm 40$ & $1.8 \pm 0.6$ & 250 & $8 \pm 0.9$ \\
\hline Lysine & $610 \pm 20$ & $1.8 \pm 0.8$ & 220 & $4.5 \pm 1$ \\
\hline Peptide PN & $640 \pm 20$ & $2.1 \pm 0.9$ & 170 & $11 \pm 1$ \\
\hline
\end{tabular}

Table 3. DPV peak characteristics extracted from results obtained on as-grown $a-\mathrm{CN}_{0.26}$ : peak potential, peak area, peak current density, and full-width at peak mid-height for the different CBIR (see Figure 3). 
Table 4

\begin{tabular}{ccccc}
\hline CBI-R & $E_{\mathrm{p}}(\mathrm{mV} / \mathrm{SCE})$ & Area $\left(10^{-5}\right)$ & $L_{1 / 2}(\mathrm{mV})$ & $J_{\mathrm{p}}\left(10^{-4} \mathrm{~mA} \mathrm{~cm}^{-2}\right)$ \\
\hline Serine & $590 \pm 5$ & $3.5 \pm 0.5$ & 180 & $2.9 \pm 0.7$ \\
\hline Threonine & $580 \pm 3$ & $4.5 \pm 0.5$ & 150 & $2.8 \pm 0.5$ \\
\hline Histidine & $570 \pm 5$ & $4.0 \pm 0.3$ & 170 & $2.5 \pm 0.3$ \\
\hline Lysine & $537 \pm 3$ & $5.3 \pm 0.5$ & 140 & $2.9 \pm 0.2$ \\
\hline Peptide PN & $552 \pm 3$ & $4.4 \pm 0.4$ & 100 & $3.2 \pm 0.6$ \\
& & & & \\
\hline
\end{tabular}

Table 4. DPV peak characteristics extracted from results obtained on pre-treated $a-\mathrm{CN}_{0.26}$ : peak potential, peak area, peak current density, and full-width at mid-height for the different CBI-R (see Figure 4). 


\section{Table 5}

\begin{tabular}{lcc}
\hline & Multiplicative factor for the peak area & Multiplicative factor for $J_{\mathrm{p}}$ \\
\hline Serine & 3.9 & 9.4 \\
\hline Threonine & 3.5 & 6.8 \\
\hline Lysine & 2.9 & 6.4 \\
\hline histidine & & 3.1 \\
\hline Peptide PN & 2.2 & \\
\hline
\end{tabular}

Table 5. Multiplicative factors for area and peak current density for the different CBI-R. 


\section{Scheme}

\section{Scheme 1}<smiles>O=Cc1cc2ccccc2cc1C=O</smiles><smiles>[R]n1cc2cc3ccccc3cc2c1C#N</smiles>

Scheme 1. Derivatization reaction of primary amine by NDA. 
Scheme 2<smiles>N#Cc1c2cc3ccccc3cc2cn1C(CO)C(=O)O</smiles>

CBI-serine<smiles>CC(O)C(C(=O)O)n1cc2cc3ccccc3cc2c1C#N</smiles>

CBI-threonine<smiles>N#Cc1c2cc3ccccc3cc2cn1C(Cc1c[nH]cn1)C(=O)O</smiles><smiles>N#Cc1c2cc3ccccc3cc2cn1CCCCC(N)C(=O)O</smiles>
CBI-lysine<smiles>CCOCCN(CC)CCn1cc2cc3ccccc3cc2c1C#N</smiles>

CBI-PN

Scheme 2. Studied amino acids and peptide (PN). 
Scheme 3

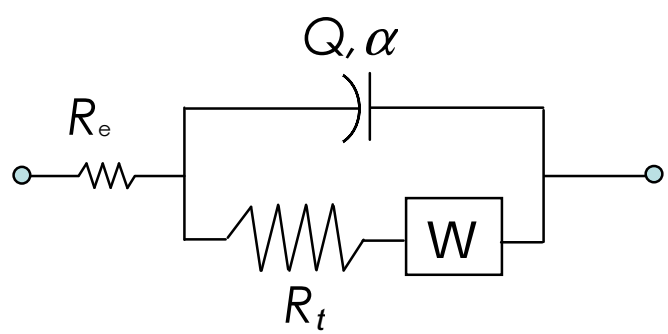

Scheme 3. Electrical equivalent circuit proposed, where $R_{\mathrm{e}}, Q, R_{\mathrm{t}}$, and $W$ are attributed to the electrolyte resistance, the non ideal capacitance, the charge transfer resistance and the Warburg diffusion impedance, respectively. 


\section{Figures}

\section{Figure 1}

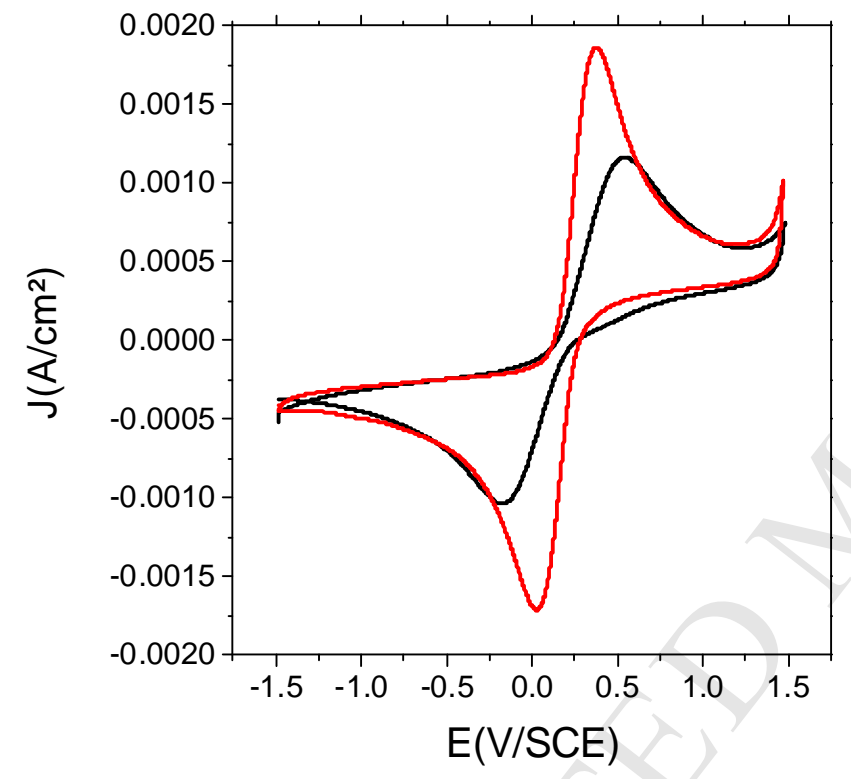

Fig. 1: $\mathrm{CV}$ responses of an $a-\mathrm{CN}_{0.26}$ electrode using a $50 \mathrm{mV} \mathrm{s}^{-1}$ scan rate in a $0.5 \mathrm{M} \mathrm{KCl}$ aqueous solutions containing equimolar concentrations $(10 \mathrm{mM})$ of $\left[\mathrm{Fe}(\mathrm{III})(\mathrm{CN})_{6}\right]^{3-}$ and $\left[\mathrm{Fe}(\mathrm{II})(\mathrm{CN})_{6}\right]^{4-}$. Black curve : $\mathrm{CV}$ on as-grown $a-\mathrm{CN}_{0.26}$; Red curve : $\mathrm{CV}$ on pre-treated $a-\mathrm{CN}_{0.26}$ (See protocol in the text). 
Figure 2

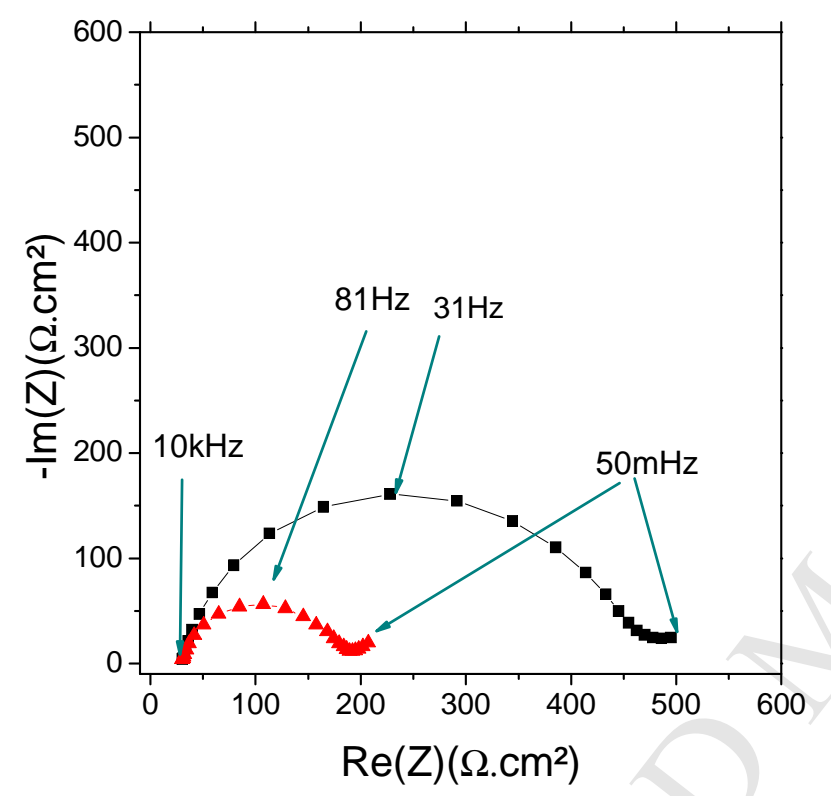

Fig. 2: EIS spectra of $a$ - $\mathrm{CN}_{0.26} \mathrm{WE}$ disk electrode using $10 \mathrm{mV}$ as $\mathrm{AC}$ signal excitation and 0.21 $\mathrm{V} / \mathrm{SCE}$ as DC potential which corresponds to the equilibrium potential of a $0.5 \mathrm{M} \mathrm{KCl}$ aqueous solutions containing equimolar concentrations $(10 \mathrm{mM})$ of $\left[\mathrm{Fe}(\mathrm{III})(\mathrm{CN})_{6}\right]^{3-}$ and $\left[\mathrm{Fe}(\mathrm{II})(\mathrm{CN})_{6}\right]^{4-}$. Black curve: EIS spectra for as-grown $\mathrm{CN}_{0.26}$; Red curve : EIS for pre-treated $a$ - $\mathrm{CN}_{0.26}$ (see protocol in the text). 
Figure 3

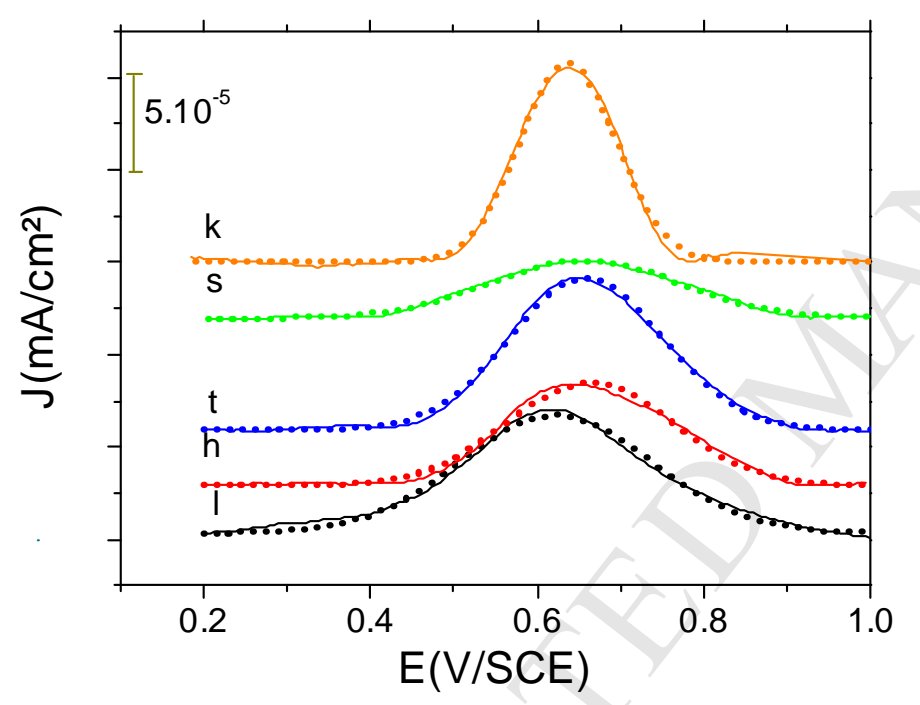

Fig.3: DPV curves obtained at $25 \mathrm{mV} \mathrm{s}^{-1}$ on as-grown $a-\mathrm{CN}_{0.26}\left(\mathrm{~S}=0.282 \mathrm{~cm}^{2}\right)$ in a $100 \mathrm{mM}$ borate buffer $(\mathrm{pH} 9) / \mathrm{MeOH}(50 / 50 \mathrm{v} / \mathrm{v})$ solution, with $\mathrm{NDA} / \mathrm{CN}=1$ and NDA/(AA or PN $)=100$ derivation ratios, respectively. (h) CBI-histidine (l) CBI-lysine (t) CBI-threonine (s) CBI-serine (k) CBI-PN. The solid lines correspond to the experimental voltammograms and dotted lines to simulations based on a standard Gauss curve. $[\mathrm{AA}]$ or $[\mathrm{PN}]_{\mathrm{f}}=25 \mu \mathrm{M}$. 
Figure 4

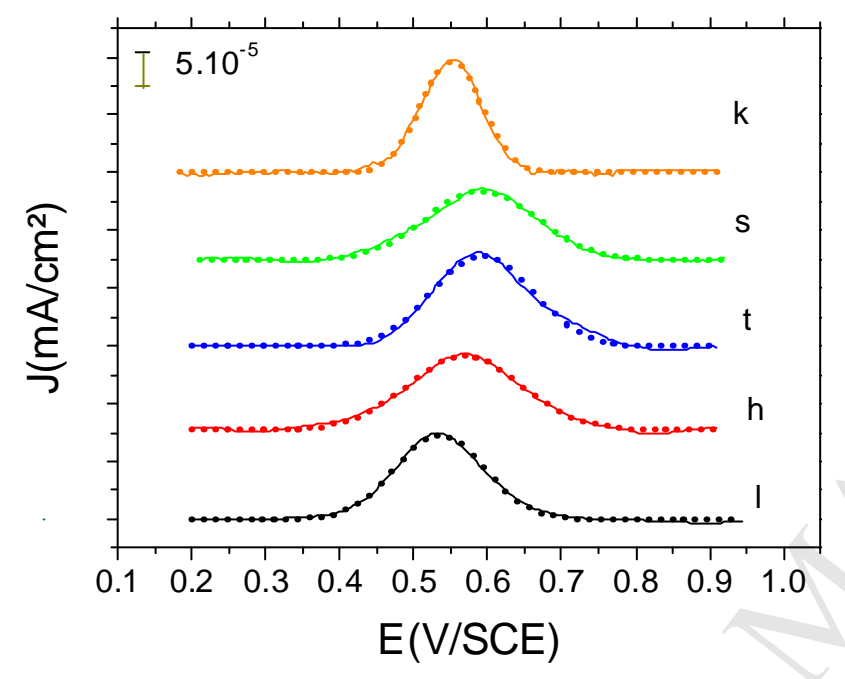

Fig.4: DPV at $25 \mathrm{mV} \mathrm{s}^{-1}$ on pre-treated $a-\mathrm{CN}_{0.26}\left(S=0.282 \mathrm{~cm}^{2}\right)$ in a $100 \mathrm{mM}$ borate buffer $(\mathrm{pH}$ 9) $/ \mathrm{MeOH}(50 / 50 \mathrm{v} / \mathrm{v})$ solution, with $\mathrm{NDA} / \mathrm{CN}=1$ and NDA/(AA or PN) $=100$ derivation ratios, respectively. (h) CBI-histidine (l) CBI-lysine (t) CBI-threonine (s) CBI-serine (k) CBI-PN. The solid lines correspond to the experimental voltammograms and dotted lines to simulations based on a standard Gauss curve. $[\mathrm{AA}]$ or $[\mathrm{PN}]_{\mathrm{f}}=25 \mu \mathrm{M}$. 
Figure 5

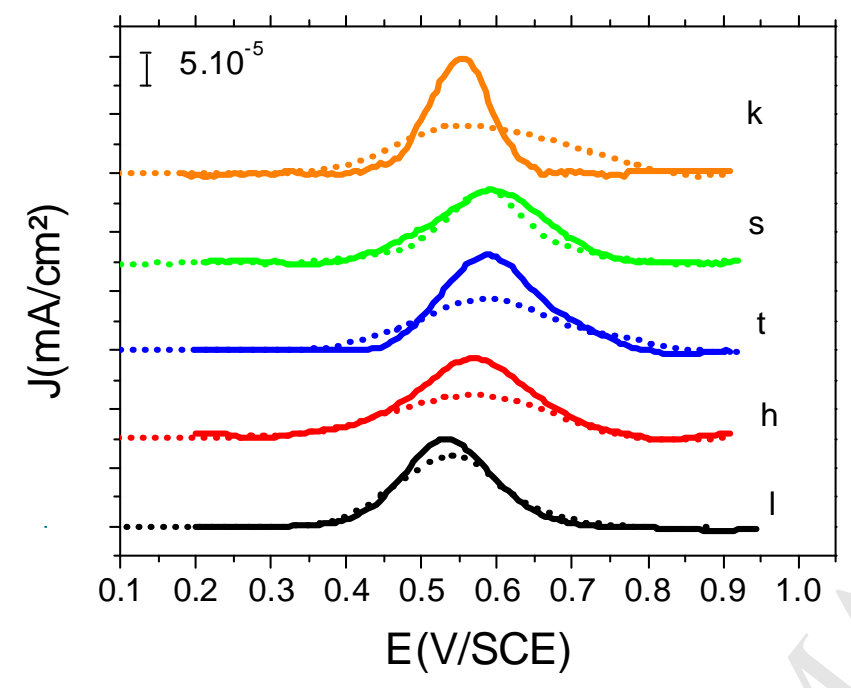

Fig.5: DPV comparison for results obtained on pre-treated $a-\mathrm{CN}_{0.26}$ and on GC at $25 \mathrm{mV} \mathrm{s}^{-1}$ with a $100 \mathrm{mM}$ borate buffer $(\mathrm{pH}$ 9) $/ \mathrm{MeOH}(50 / 50 \mathrm{v} / \mathrm{v}$ solution with NDA/CN $=1$ and NDA/(AA or $\mathrm{PN})=100$ derivatization ratios, respectively. (h) CBI-histidine (l) CBI-lysine (t) CBI-threonine (k) CBI-PN. Full line: pre-treated $a-\mathrm{CN}_{0.26}\left(\mathrm{~S}=0.282 \mathrm{~cm}^{2}\right)$. Dashed line: $\mathrm{GC}\left(\mathrm{S}=0.071 \mathrm{~cm}^{2}\right)$. 
Figure 6
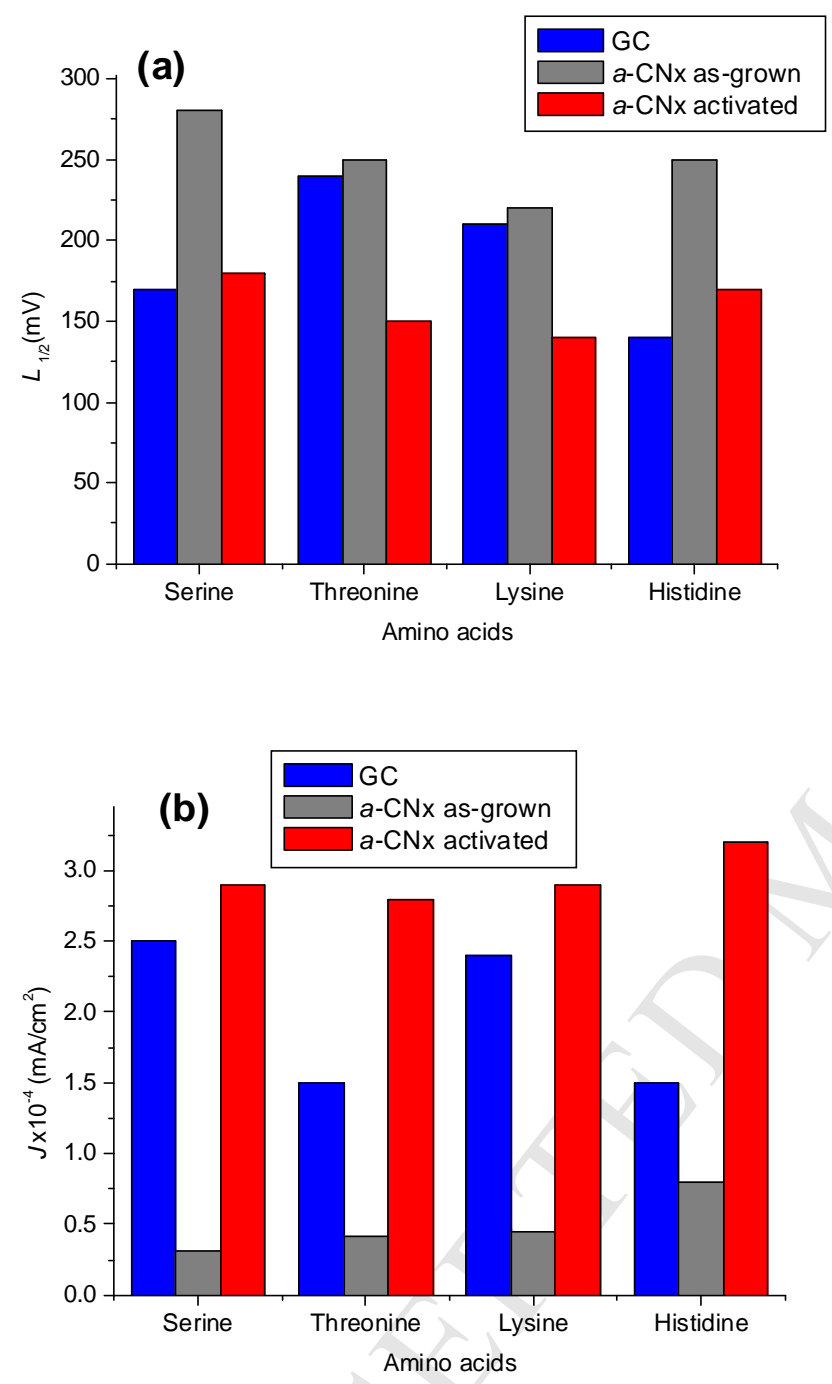


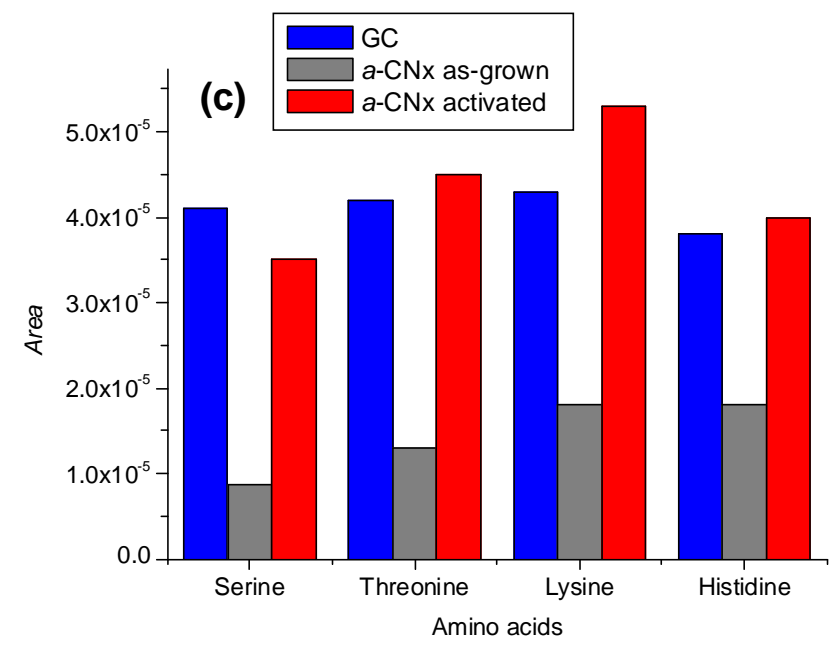

Fig.6: Comparison of DPV characteristic values for CBI-AA (AA= lysine, threonine, serine and histidine) on each electrode: $\mathrm{GC}$, as-grown $a-\mathrm{CN}_{0.26}$ and pre-treated $a-\mathrm{CN}_{0.26}$. A. $L_{1 / 2}$ values. B. $J_{\mathrm{p}}$ values. C. Area values. 